\section{Therapeutic Results}

Sulphanilamide did not completely arrest the development of generalized tuberculosis. The lesions of the treated animals that died during the fourth or fifth week of the experiment appeared to be less than those of controls. All the survivors were killed on the fortysecond day, when the differences between the groups were as follows :

\section{human Strain, R. 2}

The spleens of the control animals were very friable, but those of the treated animals were of almost normal texture. Although macroscopic tuberculous foci were present in the spleens of all the guinea-pigs, they were fewer, much smaller, and showed less tendency to coalesce in the treated group. Spleens from nine controls and nine treated animals were sectioned by Dr. C. L. Oakley, who reported that "tubercles were present in all, but were consistently smaller and showed less tendency to coalesce in the treated animals than in the controls. In many spleens from control animals no normal splenic tissue could be found ; in most of the treated animals each tubercle was surrounded by a broad zone of more or less normal spleen. In no instance was there the slightest sign of healing."

In the third series of experiments of Rich and Follis no animals in the fifth week and only one of six animals in the sixth week in the treated group showed macroscopic lesions in the spleen, although all except one showed scattered microscopic tubercles. This is a better result than we were able to obtain in our preliminary experiment.

The spleens of our treated animals (average area of anterior surfaces, $460 \mathrm{sq}$. $\mathrm{mm}$.) were less enlarged than those of the untreated controls (average, 822 sq. $\mathrm{mm}$.), but this difference was probably partly due to the fall in weight of those treated. Our colleague, Dr. J. W. Trevan, kindly examined the data statistically, and concluded that the size of the spleen did not provide any important evidence as to the intensity of infection.

Many tuberculous foci were present in the lungs of both our treated and untreated animals, but they were somewhat fewer and more discrete in the former group, and had less associated basal consolidation. The inguinal and tracheobronchial lymphatic glands were much smaller and not so caseous in treated guinea-pigs.

The livers of many animals showed macroscopic lesions, and the variation in the extent of the infection in the treated and control groups was slight. There were no significant differences in the amounts of pus in the local lesions at the site of inoculation.

\section{BOVINE STRAIN, BV. 28}

Treatment had possibly a slight inhibitory effect in guineapigs-less than was obtained in the experiment with the less virulent human strain, R. 2.

A companion experiment in rabbits showed no evidence of inhibition of tuberculosis with treatment. Eight control and eight treated animals were used, $3,750 \mathrm{mg}$. of the drug being administered daily to each treated rabbit in divided dosage.

\section{Summary and Conclusions}

Sulphanilamide appears to produce some degree of inhibition of an infection of guinea-pigs with a human strain of the tubercle bacillus. Our results are less striking than those of Rich and Follis-possibly due to a difference in strain.

The drug had very little influence on the course of infection in guinea-pigs and none in rabbits when a bovine strain was used.

We agree with Rich and Follis that it would be regrettable if any premature and unjustifiable conclusions were drawn regarding the treatment of tuberculosis. Further prolonged investigations with sulphanilamide and other preparations are clearly necessary under carefully controlled conditions, special attention being paid to the toxicity of the drugs employed.

We are indebted to Dr. A. Stanley Griffith for the virulent bovine strain, BV. 28, and to Drs. J. W. Trevan and C. L. Oakley for their valuable help.

\section{REFERENCE}

Rich, A. R., and Follis, R. H. (1938). Johns Hopk. Hosp. Bull., 62, 77.

\section{THE SARCOIDOSIS OF BOECK}

\section{BY}

\section{R. BODLEY SCOTT, M.A., D.M., M.R.C.P.}

First Assistant, Medical Professorial Unit, St. Bartholomew's Hospital; Assistant Physician, Woolwich War Memorial Hospital

(With Special Plate)

The individual lesions of sarcoidosis have been recognized for many years, but, as patients would seek the advice of the dermatologist for one, the general physician for another, and the ophthalmologist for a third, the synthesis which showed them all to be expressions of the same morbid process was long delayed. However, the concepi of a generalized disease with infiltrations of the skin in only a moiety of the cases is now widely admitted. Jonathan Hutchinson (1875) was the first to recognize the complaint, although priority is usually given to other workers-Besnier (1889), Tenneson (1892), and Boeck (1899). He "was accustomed ... to designate the condition Mabey's malady "-from the name of his patient" and although other and more scientific names might be devised, it is perhaps doubtful whether they would be more convenient" (1900). Longcope and Pierson (1937) quote nine other synonyms, and their.list is by no means exhaustive. In the present paper the term "sarcoidosis of Boeck" is used, not for its intrinsic merit, which is little, but because it is familiar and bears no causative connotation.

The sarcoidosis of Boeck is a disease of long duration with a tendency to spontaneous remission; it is characterized by enlargement of lymph-nodes and spleen, by infiltrations of the skin, lungs, and bones of the fingers, by enlargement of parotid and lacrimal glands, and by iridocyclitis. One or more of these changes may be present in any individual case. It is my purpose to describe the clinical picture of the disease and to present very briefly eight new cases.

Sarcoidosis is not a rare disease, but it is difficult to give its frequency numerical expression as the patients are scattered through the special departments of a hospital. In over 300 histological examinations of lymph-nodes excised to establish a diagnosis of Hodgkin's disease, sarcoidosis was found once to every eleven cases of lymphadenoma; when to these are added the patients who attend the dermatologist for cutaneous sarcoid and some cases of "tuberculous" iridocyclitis from the ophthalmologist, it will be appreciated that its frequency demands for it a wider recognition. The eight cases reported here were collected in less than a year.

\section{The Clinical Picture}

The course of the disease is one of extreme chronicity unaccompanied in the majority by such symptoms of intoxication as pyrexia or emaciation, although there may be comp dint of tiredness. The patient commonly comes 
under observation on account of enlargement of lymphnodes, or, if some other manifestation provides the first symptom, lymphadenopathy is found. The initial complaints in the present cases are tabulated below:

\begin{tabular}{lcccc|ccc} 
Lymphadenopathy & $\ldots$ & $\ldots$ & 2 & Swelling in breast .. & $\ldots$ & 1 \\
Cutaneous lesions & $\ldots$ & $\ldots$ & 2 & Swelling of parotid & and & \\
Cough &. & $\ldots$ & $\ldots$ & 1 & lacrimal glands .. & $\ldots$ & 1 \\
Tiredness &.. & $\ldots$ & $\ldots$ & 2 & Swelling of fingers.. &.. & 1
\end{tabular}

Gradually other lesions appear while the earlier ones involute, and this process may continue over a number of years, tending often towards complete recovery.

\section{Lymphadenopathy and Splenomegaly}

Enlargement of superficial lymph-nodes is present at some stage in all cases; it is usually generalized and of moderate degree, but on occasions it is limited to one group of nodes and is of such an order as to raise the suspicion of Hodgkin's disease. The enlarged nodes are painless and insensitive, discrete and mobile; while the patient is under observation they may retrogress and become impalpable. Splenomegaly is common and may sometimes be considerable. The spleen was palpable in five of the present cases. It is probable that some of the cases reported as tuberculous splenomegaly with miliary tuberculosis of the lungs (Hickling, 1938) are instances of sarcoidosis.

\section{Cutaneous Lesions}

The infiltrations of the skin are often so bizarre that they have attracted much attention in the past, and in consequence sarcoidosis was for years regarded as a disease of the skin with occasional visceral manifestations. The frequency of these lesions is difficult to compute, but it is probable that they are found in not more than 50 per cent. of all cases of sarcoidosis; clinically the cutaneous lesions fall into four groups:

1. Miliary Lupoid (Boeck, 1899, 1905).-This occurs in two forms: first as an eruption of small red-brown papules affecting the cheeks, forehead, extensor surfaces of the arms, the buttocks, and the back of the legs. The papules are usually smooth, but may show hyperkeratosis. This fine form of miliary lupoid occasionally occurs in plaques resembling lichen planus (lichenoid variety). The second form is the nodular sarcoid where lesions occur most frequently on the face and limbs. The nodules during the stage of eruption may reach a diameter of $5 \mathrm{~cm}$.; they are smooth, slightly elevated, and red-blue in colour; in the florid stage, which may last twenty years, they increase in volume, become violaceous, and the surface, which never ulcerates, is often telangiectatic. The whole process is one of extreme torpidity. In the stage of involution, central flattening gives rise to an annular appearance, and telangiectasis and pigmentation of the margins are common.

2. Lupus Pernio (Besnier, 1889 ; Tenneson, 1892).-This is a diffuse infiltrative lesion affecting the nose, cheeks, and sometimes the lobes of the ears. The eruption has a sharp border with a surface which may appear almost burnished. Perniotic lesions of the fingers with associated bone changes are common.

3. Angio-Lupoid (Brocq and Pautrier, 1913).-This lesion is less common. It occurs in women of middle age, and consists of soft infiltrated plaques on the sides of the root of the nose, violet-red in colour with marked telangiectasis.

4. Érythrodermie Sarcoïdique (Schaumann, 1924) appears as large superficial serpiginous red areas on the front of the legs and thighs.
An isolated lesion of the skin, especially of the types described as miliary lupoid and angio-lupoid, is not always sufficient for a diagnosis of sarcoidosis, as cutaneous infiltrations which are macroscopically and microscopically identical may be due to other causes. These causes are leprosy (tuberculoid type; Motta, 1931), leishmaniasis ("bouton d'orient"; Dupont, 1930), and possibly tuberculosis and syphilis. Of the cases reported here four had skin eruptions at one time or another. Case I showed the coarse nodular sarcoid, Cases III and VII the fine miliary lupoid, and Case VIII was an example of litpus pernio.

\section{Pulmonary Lesions}

The intrathoracic changes are of two types: first and most common is the enlargement of mediastinal or hilar lymph-nodes, which may be sufficient to simulate Hodgkin's disease, although in sarcoidosis the hilar lymphadenopathy predominates, while in lymphadenoma the form is more commonly mediastinal. The second type of lesion is seen radiographically as a diffuse mottling throughout the lung fields, simulating that of miliary tuberculosis but usually coarser and less regularly disposed. There is evidence to show that this miliary lesion may result in pulmonary fibrosis and even produce heart failure. Five of the present cases showed hilar or mediastinal lymphadenopathy, and one the miliary change. It is remarkable that these extensive radiographic abnormalities are accompanied by so few symptoms and physical signs; cough was a feature of two cases, but there were no sputa, and the physical signs were limited to basal crepitation. It seems possible, as Bödecker (1932) has suggested, that some of the cases reported as chronic miliary pulmonary tuberculosis may be examples of this disease. (Plate, Figs. 1, 2, and 3.)

\section{Bones}

The changes occur almost exclusively in the phalanges of the hands and feet. Clinically they make their appearance as painful fusiform swellings of the fingers. The radiographic changes were fully described by Jüngling (1920) as osteitis multiplex cystica vel cystoides tuberculosa, although they had been recognized eighteen years previously by Kienbock (1902) and their association with lupus pernio noted by Kreibech (1904). The normal structure of the phalanx is replaced by a lace-like network with small areas of rarefaction often surrounded by a zone of increased density. On occasion these radiographic changes are unaccompanied by clinical evidence of disease, but the process may advance to cause mutilation or may heal so completely that the finger appears normal except for some deformity of the nail. Osteitis multiplex occurred in two of the present series (Fig. 4).

\section{Other Lesions}

Enlargement of the parotid and lacrimal glands has often been noted; in this series the parotid glands were enlarged in one, and the lacrimal glands in one, and both parotid and lacrimal glands in a third case. This patient presented the clinical picture of Mikulicz's syndrome. Three of Longcope and Pierson's cases showed affections of one or other of these glands.

Iridocyclitis is stated to occur in about 10 per cent. of cases of sarcoidosis (Blegvad, 1931); it is of the type described as "tuberculous" or "paratuberculous." This affection is often resistant to treatment, and may lead to blindness, as in one of the two cases affected in this series. Other ocular lesions are uncommon, but Blegvad (1931) has reported infiltration of the conjunctiva. 
Several writers have suggested that the uveo-parotid syndrome of Heerfordt (1909) is inseparable from sarcoidosis; the histological changes are identical, and a perusal of case reports shows that all gradations, from iridocyclitis with swelling of the parotid glands to the well-known clinical picture of miliary lupoid, occur. Pautrier (1938) and Slot, Goedbloed, and Goslings (1938) have teported cases which show clearly that uveo-parotitis must be regarded as a clinical variant of sarcoidosis.

Infiltrations in many other sites have been recorded, but those already described occur often enough to constitute an easily recognizable picture. Boeck (1916) and Mylius (1928) have stressed the frequency of lesions in the mucosae of the upper air passages; the breast was involved in one of the present cases and in one seen by Goeckermann (1928). There are records of lesions in the testicle (Pautrier, 1935), the hypophysis (Schaumann, 1936), and the optic nerve (Reis and Rothfeld, 1931).

\section{Treatment}

It is difficult to evaluate the results of treatment in a disease which so often shows spontaneous involution. Radiotherapy, gold, arsenic, and tuberculin are generally held to be useless, although improvement followed the first two in some of the present cases. Lomholt (1937) has reported benefit from antileprol.

\section{Pathology}

The observation that a negative Mantoux reaction is common in sarcoidosis has given rise to much speculation. It has been urged that it is an instance of cutaneous "anergy" (Martenstein, 1924), but it has never been established that the reaction is negative more frequently than in a series of normal controls, and Kissmeyer (1932) concludes that the percentage of negative reactions is what would be expected in non-tuberculous subjects of the same age. The proportion of negative tests in different series varies considerably.

Anaemia is mild or absent, and examination of the blood often reveals a moderate mononucleosis; two of the present cases showed an eosinophilia such as was noted by Longcope and Pierson (1937). An increase in the plasma globulin has been observed by Salvesen (1935), and was present in one of my patients.

The histological changes are identical in all the affected tissues. There is a proliferation of histiocytes to form discrete collections of epithelioid cells, among which an occasional giant cell may be seen. Surrounding lymphocytic infiltration is lacking; there is no caseation, and tubercle bacilli cannot be demonstrated. The lesions may be said to consist of "pathological tubercles," and the changes are familiar to all morbid anatomists under the name of hyperplastic or endothelial " tuberculosis," although a more accurate descriptive term would be histiocytic sinus reticulosis (Fig. 5).

\section{Aetiology}

An acrimonious dispute over the nature of sarcoidosis has been in progress for many years. Three hypotheses have been adduced: first, that it is due to tuberculosis; secondly, that it is a non-specific tissue response which may be evoked by a variety of pathogenic agents such as the tubercle and lepra bacilli, the Spirochaeta pallida, and leishmania; and, thirdly, that it is a systematized disease of lympho-reticular (reticulo-endothelial) tissue comparable to Hodgkin's disease and similarly of unknown aetiology. The first hypothesis has been favoured by dermatological opinion; but inoculation experiments, with a few doubtful exceptions, have been consistently negative, and acid-fast bacilli have been demonstrated only in a handful of cases, all of which Kissmeyer (1932) has shown to be open to criticism. The only facts favouring a tuberculous aetiology are the microscopical appearances, and the observations of Schaumann (1923) and others that some patients have died of phthisis. Most pathologists will admit that the histological signature of the tubercle bacillus is susceptible of forgery, and phthisis may clearly be a secondary infection in an occasional case; indeed, it is possible that the pulmonary fibrosis which sometimes occurs may be a predisposing factor. The second hypothesis also has its origin in dermatological writings, and, although it must be admitted that similar cutaneous lesions may be due to Hansen's bacillus (tuberculoid leprosy) or leishmaniasis (Dupont, 1930), it is unbelievable that the whole characteristic and well-defined syndrome of sarcoidosis could be anything but a specific disease due to one cause. The suggestion that sarcoidosis falls into the same category as leucosis and Hodgkin's disease and must rank as a reticulosis (Pullinger, 1932 ; Ross, 1933 ; Bodley Scott and Robb-Smith, 1936) is finding increasing favour, although its cause remains as obscure as that of the other diseases of this group.

\section{Case Reports}

CASE I

A married woman, this patient came of healthy stock, and had had no illness, except catarrhal jaundice in childhood, until the age of 34 years, when she noticed an eruption above the right eyebrow. Ten months later similar spots appeared on the arms, knees, and neck; she began to tire easily and sweat at night, but there was no loss of weight. On admission to hospital at the age of 35 she was apyrexial and weighed $45 \mathrm{~kg}$. The cutaneous lesions consisted of slightly raised infiltrated areas, oval or circular in shape, and in colour varying from violaceous to yellow-red. All the superficial lymph-nodes were enlarged and of an average diameter of $1 \mathrm{~cm}$. The spleen extended $5 \mathrm{~cm}$. below the left costal margin. A blood count showed a hypochromic anaemia with 58 per cent. haemoglobin and a normal differential count. A skiagram of the chest showed some enlargement of mediastinal nodes, and although the hands appeared normal the radiographic lesions of osteitis multiplex were found in the left middle finger. The Wassermann and Mantoux tests $(0.1 \mathrm{mg}$. O.T.) were negative, and biopsy of a cutaneous nodule showed the histological changes of sarcoidosis. She was treated with ultra-violet light and discharged.

Six months later she was readmitted. The eruption was unchanged, her weight was steady, and lymphadenopathy persisted only in the posterior cervical triangles. The spleen and liver were palpable; the anaemia had been remedied and the differential leucocyte count remained normal. She was discharged after a fortnight, and two and a half years later her condition was the same although her general health remained unimpaired.

At the age of 39 an attack of iridocyclitis, from which she made a complete recovery, was treated at an ophthalmic hospital. During the next six years she improved considerably with injections of sodium morrhuate, but developed a morning cough with sputum. In her forty-fourth, forty-fifth, and forty-sixth winters she had attacks of "pneumonia." At the age of 48 she was still troubled with morning cough and dyspnoea on exertion. Her weight was $45 \mathrm{~kg}$. The eruption had disappeared from the face, but persisted on the arms and back in the form of erythematous areas without infiltration but with an occasional yellow-brown nodule. Shotty lymphnodes were palpable in the neck, axillae, and groins, and the spleen extended $12 \mathrm{~cm}$. below the costal margin. Crepitation was audible at the base of both lungs. The hands and feet were clinically and radiographically no:mal, but skiagrams of the chest showed a diffuse fibrosis of both lungs (Fig. 3 ). 


\section{CASE II}

In this case, that of a West Indian male native, who was first seen at the age of 18 years on account of palpitations, no cardiovascular disease could be found, but there was enlargement of lymph-nodes in the neck and epitrochlear regions, and the spleen was easily palpable. His weight was $60 \mathrm{~kg}$. The patient's health remained good until the age of $19 \frac{1}{2}$ years, when for a few weeks he noted dyspnoea on exertion; his spleen was again found to be enlarged. He was free from symptoms until the age of 28 , when he developed a feverish cold, followed a week later by painful swelling of both lacrimal glands. The swellings subsided after a few days and a dry paroxysmal cough appeared. Three months later he began to tire easily; his temperature rose occasionally to $99.5^{\circ} \mathrm{F}$. and there was some dyspnoea. He had recurrent sore throat, and his left antrum was thought to be infected, but puncture led to no improvement.

He was admitted to hospital, then being 29 years old. His weight was $79 \mathrm{~kg}$. ; he was apyrexial, and his pulse frequency varied from 90 to 110 per minute. There were enlarged lymphnodes in the upper deep cervical groups and in both groins; they were discrete, firm, mobile, and of an average diameter of $1.5 \mathrm{~cm}$. A few crepitations were heard at the base of both lungs. A skiagram of the chest showed great enlargement of the hilar nodes, particularly on the right. The sputum contained no tubercle bacilli. Blood count: erythrocytes, 5,240,000 per c.mm.; haemoglobin, 90 per cent.; colour index, 0.86 ; leucocytes, 7,700 per c.mm. ; neutrophils, 60 per cent.; eosinophils, 9 per cent.; lymphocytes, 7 per cent.; plasma cells, 1 per cent.; monocytes, 14 per cent. Biopsy of a node revealed the changes of sarcoidosis, and the Wassermann reaction was negative.

He was discharged to a sanatorium, and there was a slow improvement in his condition in the next two years.

\section{CASE III}

This patient, a married woman with three healthy children, came from a healthy family and had always been well herself, although for as long as she could remember there had been "enlarged glands" in the left side of the neck. When 38 years old she noticed a painless swelling in the right breast, for which she sought admission to hospital. There were small discrete lymph-nodes palpable in the left side of the neck, and in the right breast was a hard mobile well-defined swelling measuring $5 \mathrm{~cm}$. by $4 \mathrm{~cm}$. On excision this was found to have the histological structure of sarcoid tissue, and a lymph-node showed similar changes. At this time she began to be troubled by pain in the left eye, and a year later the right one became similarly affected. At the age of $40 \frac{1}{2}$ she was readmitted: enlarged nodes were still present in the left side of the neck, and there was a swelling in the left parotid gland and paresis of the left facial nerve. The eyes showed bilateral iridocyclitis with secondary cataracts, and only perception of light was present. Lymphnodes removed from the left side of the neck showed sarcoidosis. A radiograph of the chest was normal. Left iridectomy was performed with some improvement, and a year later a similar operation was carried out on the right eye.

At the age of 42 she was blind, apart from perception of light in the left eye; enlarged nodes were palpable on both sides of the neck, and she showed the classical features of myxoedema. On the abdominal wall was one small patch of miliary lupoid. The blood picture was normal and skiagrams of the chest showed a fine diffuse fibrosis; no radiographic changes were found in the hands. With thyroid therapy her general health improved, and apart from her blindness she began to feel well.

\section{CASE IV}

This patient came of a healthy long-lived family, although his father, who died after an operation for urethral stricture, was said to have contracted syphilis before marriage. In infancy he had had scarlet fever, mumps, and chicken-pox, but was in good health until the age of $13 \frac{1}{2}$ years, when he began to feel tired at the end of the day. At this time both eyelids and both parotid glands became swollen, there was some pyrexia, and he lost weight. After three months he was admitted to a sanatorium, where he improved and gained weight: the report stated that "no signs of tuberculosis were found." Two months later he was transferred to St. Bartholomew's Hospital; he had been in bed for the previous six weeks, but felt well and was gaining weight; there was no cough. His weight was $43 \mathrm{~kg}$.; he was apyrexial, but had a tachycardia of about 100 per minute. Both parotid and both lacrimal glands were enlarged, and there was oedema of the upper lids. The tonsils were fleshy, and shotty lymphnodes were palpable in both upper deep cervical and inguinal groups. The liver extended $4 \mathrm{~cm}$. below the costal margin, and the tip of the spleen was palpable. A skiagram of the chest showed massive enlargement of hilar and mediastinal nodes. Blood count: erythrocytes, 4,970,000 per c.mm.; haemoglobin, 78 per cent. ; colour index, 0.8 ; leucocytes, 9,600 per c.mm.; neutrophils 58 per cent.; eosinophils, 5 per cent.; lymphocytes, 29 per cent.; monocytes, 7 per cent. Mantoux test (1 mg. O.T.), weak positive. The Wassermann reaction was negative. He was discharged from hospital and spent the subsequent year in Switzerland.

The patient continued to gain weight and to feel well. $\mathrm{He}$ was readmitted when 17 years old, and a node which showed the changes of sarcoidosis was removed from the groin (Fig. 5). At that time only the inguinal nodes were palpable; other physical findings were negative, but a skiagram of the chest showed little change from that of two and a half years previously.

\section{CASE V}

The patient came of healthy stock and had always been well, except for scarlet fever and mumps in childhood. At the age of 21 she married and subsequently had three pregnancies, all of which terminated in abortion. When $23 \frac{1}{2}$ years old red lumps appeared on the skin, following an attack of rheumatism; these faded after a fortnight. Six months later she developed a cough with yellow sputum; there was no sweating and no haemoptysis, but she lost $2 \mathrm{~kg}$. in weight in a month. After six weeks she was admitted to hospital: her weight was then $47 \mathrm{~kg}$. ; her temperature occasionally reached $99^{\circ} \mathrm{F}$. at night, but there was no tachycardia. Enlarged lymphnodes were palpable in both sides of the neck and in both groins; none exceeded $1 \mathrm{~cm}$. in diameter. There was flattening and reduced movement over the upper part of the right lung. Examination of the blood showed a haemoglobin of 75 per cent. and a lymphocytosis of 47 per cent. of 7,600 leucocytes per c.mm. The sputum contained no tubercle bacilli ; the Mantoux test $(0.1 \mathrm{mg}$. O.T.) and the Wassermann reaction were negative. A skiagram of the chest showed a shadow extending from the mediastinum into the right lung field, with a diffuse mottling of the right upper zone (Fig. 1); there was no radiographic abnormality of the hands. An excised node was histologically typical of sarcoidosis. The patient contracted measles while in the ward and was transferred to a fever hospital. On her return after four weeks the nodes in her neck had decreased in size, but those in the epitrochlear regions were palpable, as were some in the right costo-coracoid group. The tip of the spleen could be felt. Treatment with intravenous crisalbine was instituted, and she was discharged improved after a month. She received continued treatment as an out-patient, and a year later her weight had risen to $57 \mathrm{~kg}$., her general health was excellent, a few small nodes were still palpable, and the mediastinal mass had almost vanished.

\section{CASE VI}

A married woman aged 21 , who had always been healthy and came of sound stock, this patient had an eruption of painful red swellings on both legs which disappeared after a fortnight. About the same time she noticed a swelling in the right side of the neck; she began to lose strength, was listless, and sweated at night. Her condition remained unchanged until six months later, when swellings appeared under the chin and in the left side of the neck. These 
increased steadily in size. She had no cough, but had lost weight. At the age of 22 she was admitted to hospital; she weighed $62 \mathrm{~kg}$. and was apyrexial. All superficial lymphnodes were enlarged; the tip of the spleen was palpable and occasional rhonchi were audible in the chest. She had a moderate anaemia with 78 per cent. haemoglobin, but the blood count was otherwise normal. The Mantoux test $(0.1 \mathrm{mg}$. O.T.) and the Wassermann reaction were negative. A skiagram of the chest showed mediastinal glandular enlargement. An excised cervical node had the microscopical appearance of sarcoidosis. After radiotherapy she was discharged from hospital; the nodes were then considerably smaller, but she had lost $4 \mathrm{~kg}$. in weight.

Six months later there was further diminution in the size of the lymph-nodes, and after another three months only those in the axillae remained palpable. At this time a skiagram of the hands showed no bony lesion, but in the lungs a miliary type of infiltration (Fig. 2) had been added to the mediastinal lymphadenopathy. Her general health was good; she had regained $3 \mathrm{~kg}$., but still complained of some tiredness at the end of the day. A year after her discharge from hospital her weight was $66 \mathrm{~kg}$., she was free from symptoms, no superficial nodes were palpable, and the radiographic appearance of the lungs was normal.

\section{CASE VII}

This girl was one of a healthy family and had always been well herself, apart from childish ailments, until the age of $14 \frac{1}{2}$ years, when she noticed a small pimple on the right cheek. Six months later a painless swelling appeared in the right side of the neck, increasing slowly in size. At 16 years of age a similar lesion appeared on the left arm; a diagnosis of lupus vulgaris was made, and she was treated with injections and ultra-violet light. She lost no weight, had no fever and no sweats, and her general health was unimpaired. A year later she was admitted to hospital; she was apyrexial and without tachycardia, and her weight was $46.5 \mathrm{~kg}$. Small patches of typical miliary lupoid were present on the cheeks, arms, and back. There were enlarged lymph-nodes in both sides of the neck, the greatest measuring $2 \mathrm{~cm}$. by $3 \mathrm{~cm}$.; small nodes were palpable in both axillae and groins. The blood picture was normal; the Mantoux test $(0.1 \mathrm{mg}$. O.T.) and the Wassermann reaction were negative. She was discharged after a stay of eleven days. Eight months later she was readmitted; her weight had increased by $4 \mathrm{~kg}$, but her condition was otherwise unchanged. Skiagrams of the chest and hands were normal, and after a course of radiotherapy the lymph-nodes became smaller.

\section{CASE VIII}

A missionary worker whose father died of pulmonary tuberculosis, this patient had herself been healthy, apart from acute appendicitis, until the age of 28 , when she had sudden pain and swelling in the fourth left digit. The swelling gradually involved the whole finger, and later the left thumb and index were affected. After a few months the hand became almost normal again. At the age of 42 a red eruption appeared on the right side of the face and slowly spread over the nose and left side of the face. Six years later there was swelling of the lymph-nodes in the left side of the neck which subsided after about six months.

She was admitted to hospital when 55 years old. There was some dyspnoea on exertion, but no cough, no loss of weight, and no fever. A typical eruption of lupus pernio affected both cheeks and the nose; shotty lymph-nodes were palpable in both posterior triangles, and a persistent rale was audible at the base of both lungs. There was a fusiform swelling of the proximal phalanx of the left fourth digit, and the terminal phalanx was hyperextended. The blood picture was normal ; the Mantoux test $(0.1 \mathrm{mg}$. O.T.) and the Wassermann reaction were negative. Serum proteins: albumin 5.2 grammes and globulin 5.2 grammes per $100 \mathrm{ml}$. Skiagrams of the chest revealed some fibrosis involving particularly the right lower lobe, and the hands showed the radiographic changes of osteitis multiplex in the first and fourth left digits (Fig. 4).
She was treated with solganol-B-oleosum intramuscularly, and after seven months her health remained good, while the local lesions were unchanged.

\section{Conclusions}

1. Sarcoidosis is a systematized disease of lymphoreticular (reticulo-endothelial) tissue in which changes are found particularly in the lymph-nodes, spleen, skin, bones of the hands, lungs, eyes, and salivary glands.

2. The uveo-parotid syndrome of Heerfordt is a clinical variant of sarcoidosis.

3. Its course is prolonged and benign, and it has a tendency towards spontaneous recovery.

4. There is no convincing evidence that sarcoidosis is a manifestation of tuberculosis.

5. It is of common enough occurrence to be a disease of interest to all general physicians.

\section{Eight new cases of sarcoidosis are reported.}

I am indebted to the physicians of St. Bartholomew's Hospital for permission to make use of their cases, and to Professor Ronald Christie for much helpful and constructive criticism. This work was done during the tenure of a grant from the British Empire Cancer Campaign.

\section{REFERENCES}

Besnier, E. (1889). Ann. Derm. Syph., Paris, 2 s., 10, 333.

Blegvad, O. (1931). Acta ophthal., 9,180

Bödecker, F. (1932). Med. Klinik, 28, 929.

Boeck, C. (189y). J. cutan. Dis., 17, 543.

(1905). Arch. Derm. Syph., Vienna, 73, 71, 301.

(1916). Ibid., 121, 707.

Brocq, L., and Pautrier, L. M. (1913). Ann. Derm. Syph., Paris, 5 s., 4,1 .

Dupont, A. (1930). Ibid., 1, 453.

Goeckermann, W. H. (1928). Arch. Derm. Syph., Chicago, 18, 237

Heerfordt, C. F. (1909). Arch. Ophthal., Berlin, 70, 254.

Hickling, R. A. (1938). Quart. J. Med., N.S., 7, 263.

Hutchinson, J. (1875). Illustrations of Clinical Surgery, London, p. 42 .

- (1900). Arch. Surg., London, 11, 205

Jüngling, O. (1920). Fortschr. Röntgenstr., 27, 375

Kienbock, R. (1902). Z. Heilk., 23, 130.

Kissmeyer, A. (1932). La Maladie de Boeck. Sarcoüdes cutanées bénignes multiples, Paris.

Kreibech, K. (1904). Arch. Derm. Syph., Vienna, 70, 3

Lomholt, S. (1937). Acta derm.-venereol., 18, 131.

Longcope, W. T., and Pierson, J. W. (1937). Johns Hopk. Hosp Bull.. 60,223 .

Martenstein, H. (1924). Arch. Derm. Syph., Vienna, 147, 70.

Motta, J. (1931). Ann. Derm. Syph.. Paris, 2, 1180.

Mylius, K. (1928). Z. Augenheilk., 65, 71.

Pautrier, L. M. (1935). Presse méd., 43, 146

Pulling). Bull. Mém. Soc. méd. Hôp. Paris, 3 s., 54, 708.

Pullinger, B. D. (1932). Rose Research on Lymphadenoma, p. 115, J. Wright, Bristol

Reis, W., and Rothfeld, J. (1931). Arch. Ophthal., Berlin, 126. 357.

Ross, J. M. (1933). J. Path. Bact., 37, 311.

Salvesen, H. A. (1935). Acta med. scand., 86, 127.

Schaumann, J. (1923), Acta derm.-venereol. 3, 679.

— (1924). Brit. J. Derm. Syph., 36, 515 .

(1936). Ibid. 48, 399 .

Scott, R. Bodley, and Robb-Smith, A. H. T. (1936). St. Bart's Hosp. Rep. 69, 143 .

Slot, W. J. B., Goedbloed, J., and Goslings, J. (1938). Acta med. scand. $94,74$.

Tenneson, M. (1892). Bull. Soc. franç. Derm. Syph., 3, 417.

E. H. J. Warns (Nederl. Tijd. Geneesk., 1938, 82, 4426) treated twenty-six patients with osteo-articular tuberculosis by large doses of vitamin $\mathrm{C}$ for four and a half months, but without any therapeutic effect except possibly a slight improvement in the general condition. On the other hand, the frequently reported deficiency of vitamin $C$ in tuberculosis was confirmed: its daily consumption by the patients was three to five times the normal. There also appeared to be a certain relation between the daily consumption of vitamin $C$ and the activity of the tuberculous process. 


\section{R. BODLEY SCOTT : THE SARCOIDOSIS OF BOECK}

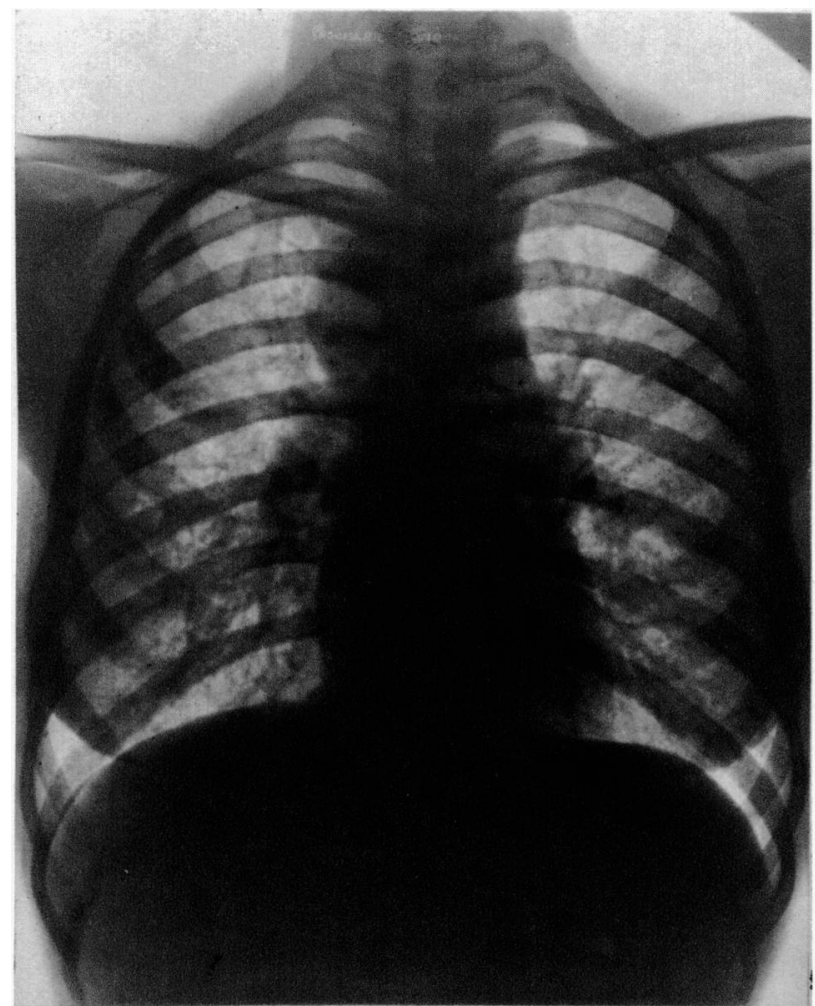

Fia. 1.-Case V. Radiograph of chest showing enlargement of mediastinal and hilar lymph-nodes.

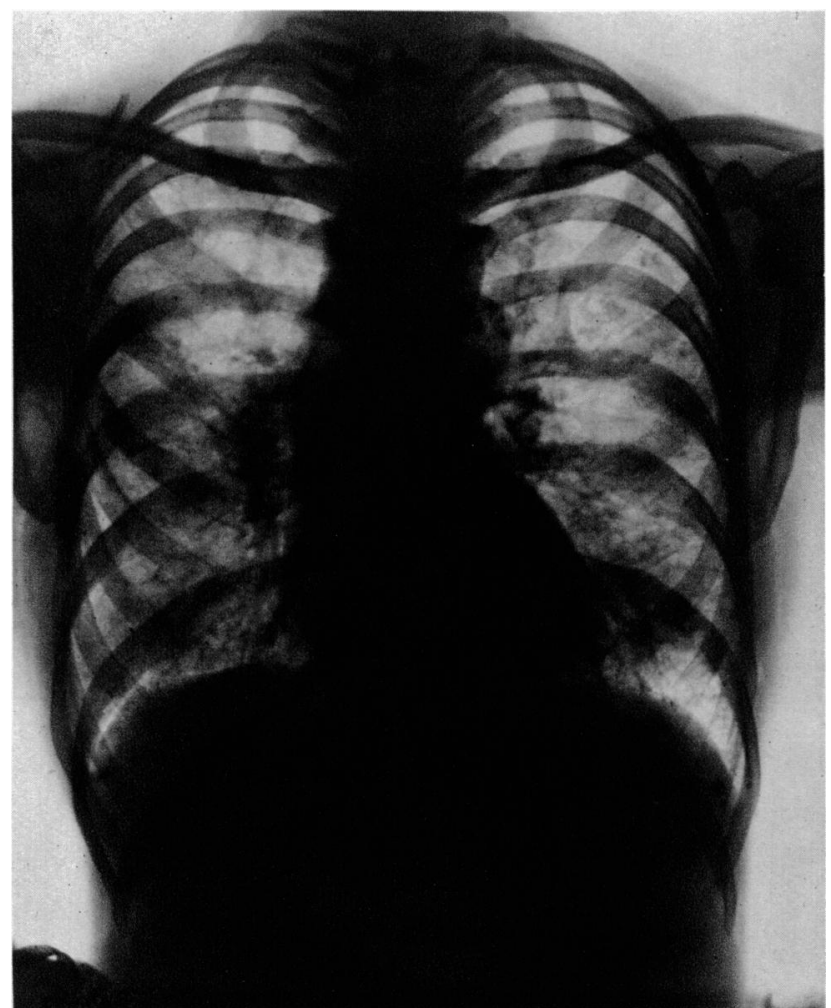

Fia. 3.-Case I. Radiograph of chest showing diffuse pulmonary flbrosis.

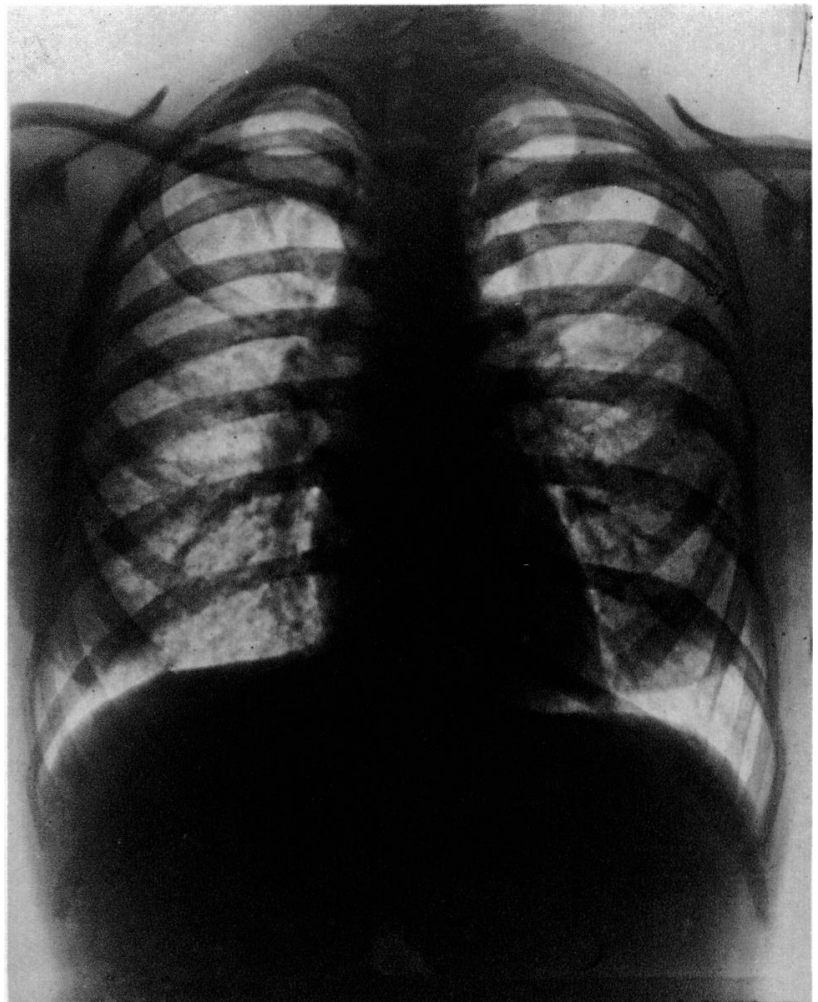

Fia. 2.-Case VI. Radiograph of chest showing enlargement of hilar lymphnodes with the miliary type of sarcold lesion.

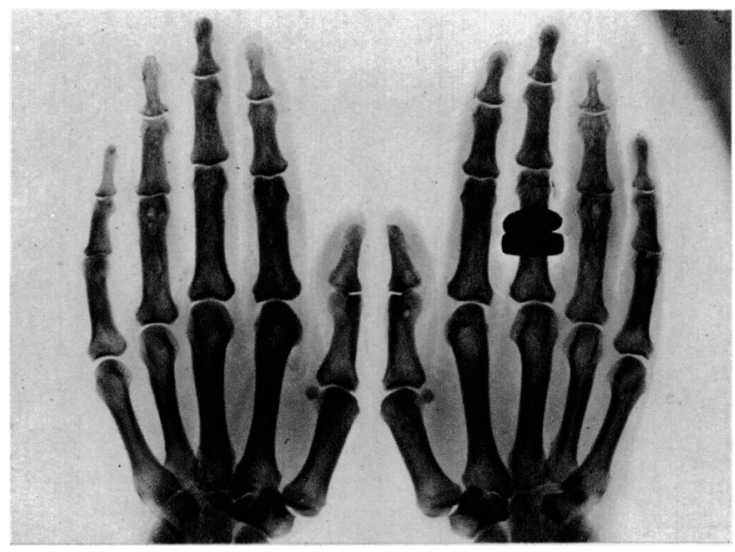

FiG. 4.-Case VIII. Radlograph of hands. Changes of osteitis multiplex are seen at distal end of proximal phalanges of left thumb and third finger and right third finger.

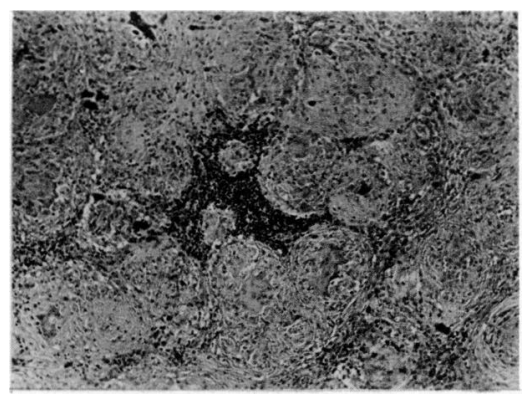

Fia. 5.-Case IV. Photomicrograph of lymphnode showing changes of sarcoidosis. 